05

\title{
Особенности структурирования и абляции тонких пленок титана фемтосекундными лазерными импульсами
}

\author{
(C) Е.В. Кузьмин, А.В. Клековкин \\ Физический институт им. П.Н. Лебедева, \\ 119991 Москва, Россия \\ e-mail: kuzmin_evg@live.ru \\ Поступила в редакцию 20.12.2021 г. \\ В окончательной редакции 20.12.2021 г. \\ Принята к публикации 30.12.2021 г.
}

\begin{abstract}
Проведено исследование процессов структурирования и абляции пленки титана фемтосекундными лазерными импульсами на длинах волн излучения 515 и $1030 \mathrm{~nm}$ как в одноимпульсном, так и в многоимпульсном режимах. Определены оптимальные энергетические режимы селективного удаления материала пленки без повреждения подложки, а также условия генерации поверхностных периодических структур. Показана эволюция периодических структур при увеличении числа лазерных импульсов. Прецизионное удаление титана связано с термомеханическими взрывным кипением и соответствующим ему вкладом энергии, обеспечивающим каскадный вид абляционных кратеров.
\end{abstract}

Ключевые слова: тонкие пленки, фемтосекундные лазерные импульсы, обработка поверхности.

DOI: $10.21883 /$ OS.2022.04.52265.66-21

\section{Введение}

Титан является распространенным конструкционным материалом. На сегодняшний день для расширения его технико-эксплуатационных преимуществ активно используется наноструктурирование и микрообработка поверхности за счет воздействия лазерных импульсов различной длительности [1]. Чаще всего при этом используется лазерная абляция [2], которая в зависимости от вложенной в материал энергии имеет несколько механизмов реализации. Один из таких механизмов откольная абляция, вызванная наличием сильных компрессионных напряжений в подповерхностном слое, возникающих из-за разности времен лазерного нагрева и времени, необходимого для расширения материала $[3,4]$. В результате откольной абляции на поверхности мишени появляются абляционные кратеры характерной формы (четкая граница кратера и плоское основание), при этом глубина кратеров не зависит от вложенной энергии, тогда как при достижении порога фазового взрыва глубина кратера быстро растет с увеличением плотности энергии излучения. Откольная абляция совместно со структурированием поверхности занимают особое место в технологиях многослойных пленок. Одна из уникальных возможностей таких процессов возможность селективно воздействовать только лишь на верхний слой многослойного образца, не повреждая нижележащие [5,6], однако поиск оптимальных режимов деликатного воздействия все еще продолжается.

В настоящем исследовании при различных энергиях в импульсе $(E)$, длинах волн $(\lambda)$, числе импульсов $(N)$ исследуются тонкие титановые пленки на кремниевых подложках. Кремний, как основной материал микро- электроники, является весьма востребованным в современном мире, а возможность управления топологией Ti/Si-пленок открывает новые перспективы для функционализации различных поверхностей. После облучения образцы исследовались методами сканирующей электронной микроскопии (СЭМ) и энерго-дисперсионной рентгеновской спектроскопии (EDX).

В качестве образцов использованы тонкие пленки титана $(30 \mathrm{~nm})$, произведенные методом магнетронного напыления при испарении высокочистого Ті на кремниевые подложки $(\mathrm{Si}\langle 100\rangle, h=0.5 \mathrm{~mm})$.

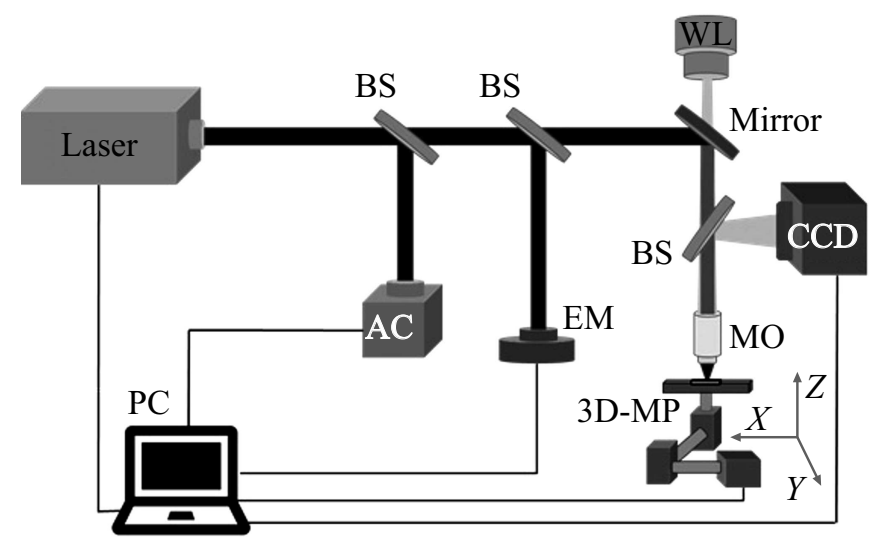

Рис. 1. Схема рабочей станции для фс/пс-лазерной абляции: $\mathrm{BS}$ - светоделитель, ЕМ - измеритель энергии, АC - автокоррелятор, $\mathrm{MO}$ - микрообъектив, WL - источник белого света, РС - компьютер с предустановленным специальным программным обеспечением для управления лазером, камерой, системой позиционирования, CCD - камера для визуализации поверхности во время сканирования. 


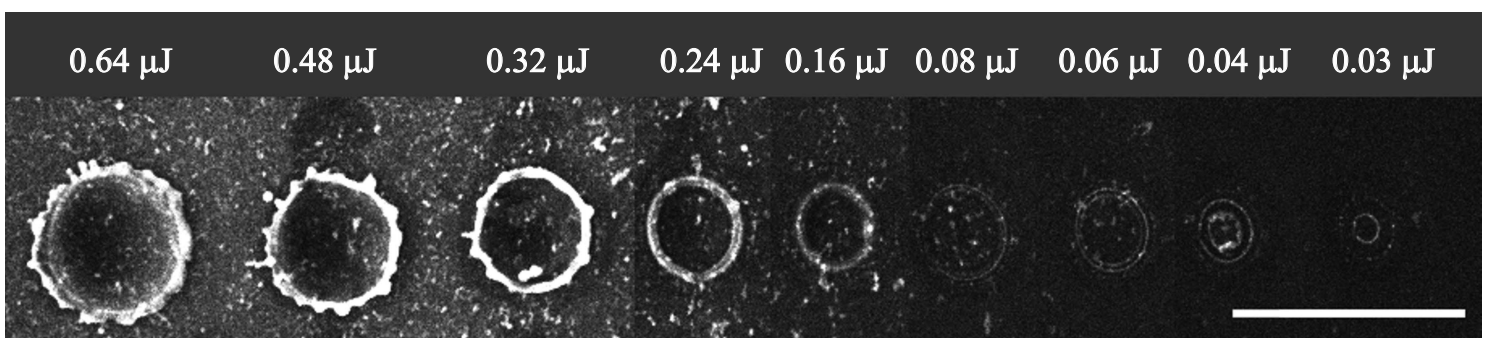

Рис. 2. СЭМ-изображение одноимпульсных кратеров, полученных при различных энергиях, $\lambda=515 \mathrm{~nm}$. Масштабная риска соответствует $10 \mu \mathrm{m}$.

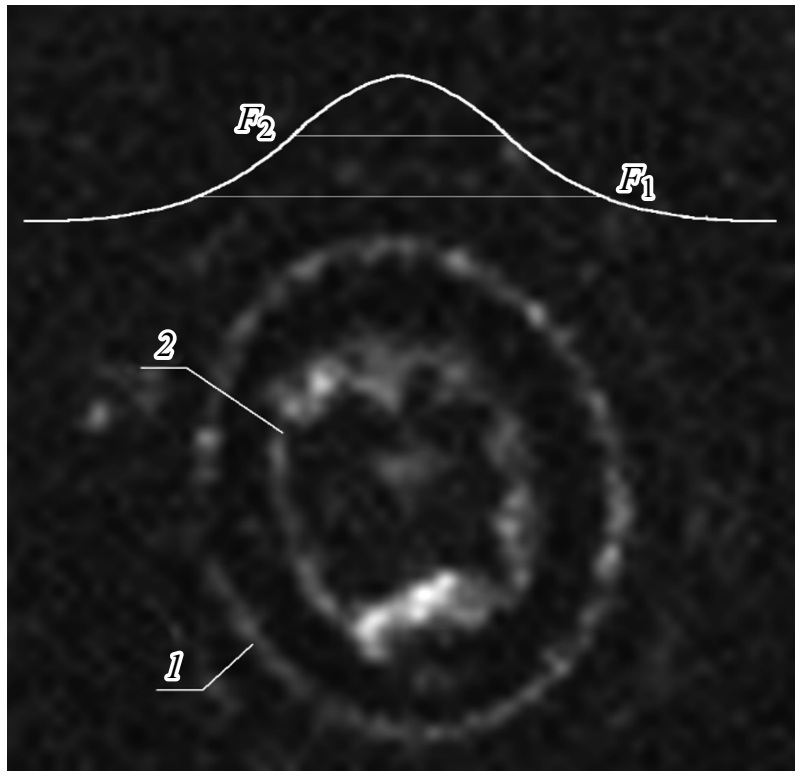

Рис. 3. Увеличенное изображение одноимпульсного кратера для энергии $0.04 \mu \mathrm{J} .1$ - граница кратера откольной абляции; 2 - граница расплавленной зоны; белой линией показана форма лазерного импульса. $F_{1}-$ порог откольной абляции, $F_{2}$ - порог плавления.

\section{Экспериментальная часть}

Обработка поверхности образца проводилось сфокусированным лазерным пучком на воздухе при нормальных условиях облучения. В качестве источника ультракоротких лазерных импульсов был использован волоконный лазер Satsuma (Amplitude Systems), генерирующий линейно-поляризованное излучение с длиной волны 515 и $1030 \mathrm{~nm}$, длительностью импульсов $300 \mathrm{fs}$ и варьируемой частотой следования импульсов вплоть до $100 \mathrm{kHz}$. Лазерное излучение с гауссовым распределением интенсивности направлялось в микроскоп и фокусировалось на образце с помощью микрообъектива $(N A=0.25)$, при этом размер фокального пятна по уровню $1 / \mathrm{e}$ составил $2.2 \pm 0.2 \mu \mathrm{m}(515 \mathrm{~nm})$ и $2.8 \pm 0.2 \mu \mathrm{m}(1030 \mathrm{~nm})$. Максимальная энергия в импульсе составила $0.64 \mu \mathrm{J}(515 \mathrm{~nm})$ и $3.3 \mu \mathrm{J}(1030 \mathrm{~nm})$, а соответствующая им максимальная плотность энергии - 3.36 и $10.09 \mathrm{~J} / \mathrm{cm}^{2}$.
Схема экспериментальной установки, используемой для лазерной абляции, приведена на рис. 1.

Для закрепления образца использовалась трехкоординатная подвижная платформа, имеющая минимальный шаг $150 \mathrm{~nm}$ и скорость перемещения вплоть до $200 \mu \mathrm{m} / \mathrm{s}$, что позволило реализовать режим одноимпульсной абляции (каждый импульс в новую точку) при непрерывном перемещении образца.

Облучение пленок производилось в двух режимах. В первом режиме осуществлялась одноимпульсная абляция при изменении энергии в импульсе, а на втором режиме изменялись не только энергия в импульсе, но и число импульсов (от 1 до 100), что позволило определить оптимальные режимы для генерации поверхностных периодических структур (ППС).

\section{Результаты и обсуждение}

На рис. 2 представлены СЭМ-изображения кратеров на поверхности титановой пленки, полученных в одно-

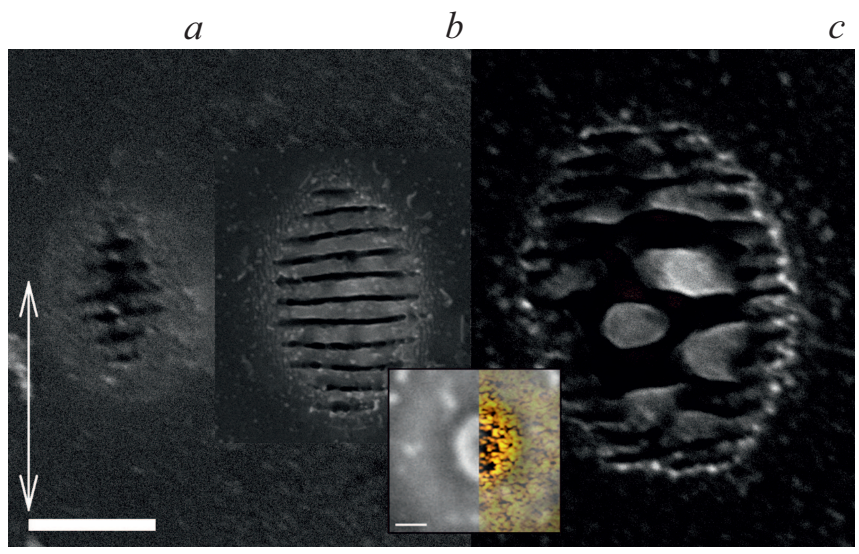

Рис. 4. СЭМ-изображение многоимпульсных кратеров $\lambda=515 \mathrm{~nm}$. Частота следования импульсов $5 \mathrm{~Hz}$. Масштабная риска соответствует $2 \mu \mathrm{m}$, поляризация излучения показана стрелкой. Энергия импульса $0.02 \mu \mathrm{J}-50$ импульсов $(a)$, $0.02 \mu \mathrm{J}-100$ импульсов $(b), 0.03 \mu \mathrm{J}-100$ импульсов $(c)$. Вставка - совмещенное CЭM/EDX-изображение поверхностных структур, полученных при $0.02 \mu \mathrm{J}$ и 100 импульсах. Масштабная риска соответствует $2 \mu \mathrm{m}$. Желтыми точками обозначены частицы титана. 


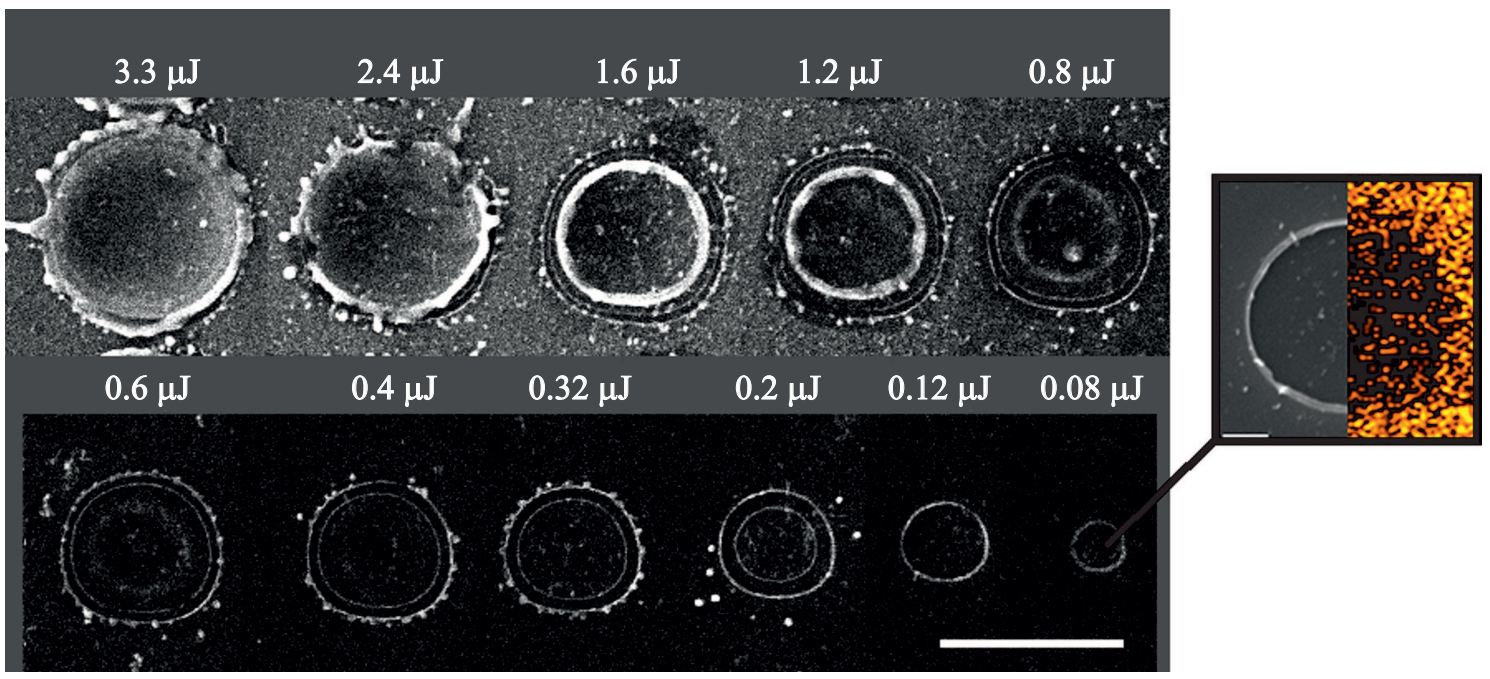

Рис. 5. СЭМ-изображение одноимпульсных кратеров, полученных при различных энергиях, на длине волны $1030 \mathrm{~nm}$. Масштабная риска соответствует $10 \mu \mathrm{m}$. Вставка: совмещенное СЭМ/EDX-изображение одноимпульсного кратера, полученного при $0.08 \mu \mathrm{J}$. Масштабная риска соответствует $2 \mu \mathrm{m}$. Желтыми точками обозначены частицы титана.

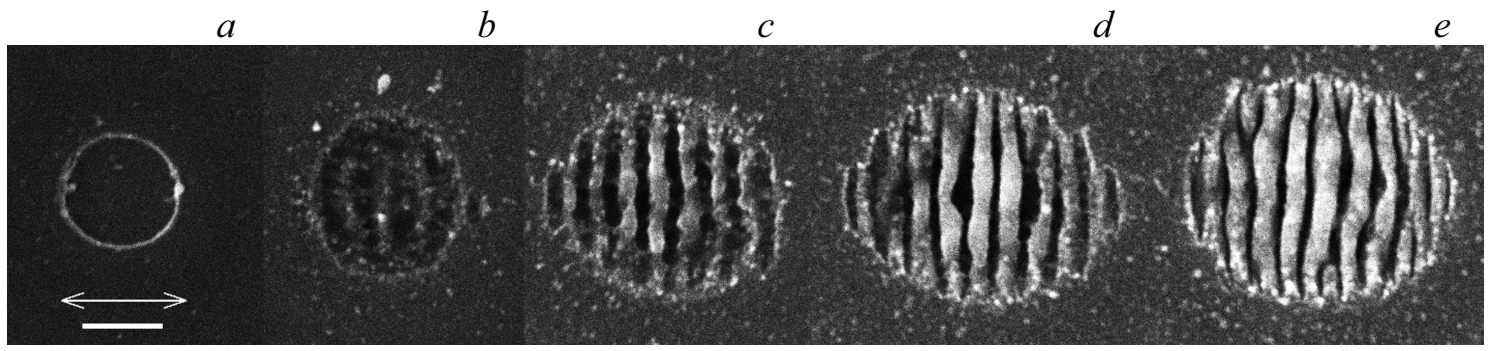

Рис. 6. СЭМ-изображение многоимпульсных кратеров $1030 \mathrm{~nm}$. Частота следования импульсов $5 \mathrm{~Hz}$. Масштабная риска соответствует $2 \mu \mathrm{m}$, поляризация излучения показана стрелкой. Энергия импульса $0.08 \mu \mathrm{J}-1$ импульс $(a)$, $0.08 \mu \mathrm{J}-$ 10 импульсов $(b), 0.08 \mu \mathrm{J}-30$ импульсов $(c), 0.08 \mu \mathrm{J}-50$ импульсов $(d), 0.08 \mu \mathrm{J}-100$ импульсов $(e)$.

импульсном режиме, при облучении на длине волны $515 \mathrm{~nm}$. Заметно, что при увеличении вложенной энергии изменяется не только размер абляционных кратеров, но и их вид, что подтверждает реализацию различных механизмов абляции.

Так, самым низкоэнергетичным из наблюдаемых режимов модификации поверхности является режим откольной абляции $(0.03-0.08 \mu \mathrm{J})$. В таком режиме (рис. 3), энергия лазерного импульса в центре фокального пятна превышает порог плавления материала, что приводит к формированию кратера с окружающим его кольцом перезастывшего материала. При этом в том же импульсе энергия по краям фокального пятна недостаточна для плавления, но превышает порог откольной абляции, что выражается в появлении кратера с плоским основанием вокруг зоны расплава [7].

Увеличение энергии в импульсе $(0.16-0.32 \mu \mathrm{J})$ приводит к росту диаметра кратера откольной абляции, однако также повышается и „остаточная“ энергия лазерного импульса, благодаря которой увеличивается размер расплавленной „внутренней“ зоны, и в дальнейшем происходит слияние двух границ кратеров, при этом чем больше вложенная энергия, тем грубее становится форма кольца перезастывшего материала. При максимальной энергии в импульсе $(0.48-0.64 \mu \mathrm{J})$ в центре кратера образуется ванна расплава, которая при окончании термических процессов формирует ,линзу“.

При многоимпульсном облучении образца на поверхности пленки происходит формирование ППС, при этом более успешная генерация происходит при низких энергиях и большом числе импульсов.

Так, при облучении 50 импульсами с энергией $0.02 \mu \mathrm{J}$ (рис. 4,a) в центре зоны облучения (где энергия максимальна) начинают формироваться поверхностные структуры с периодом $\Lambda \sim 0.36 \mu \mathrm{m}$. При увеличении числа импульсов (рис. $4, b)$ условия генерации становятся более благоприятными (сформированные ранее структуры выступают в качестве затравочных), и упорядоченность формирования ППС повышается. При этом энергия индивидуального импульса не превышает порог откольной абляции, и возбуждение поверхностных волн и, таким образом, создание ППС происходит непосредственно в тонкой пленке, что подтверждается наличием периоди- 
ческих следов титана в центре кратера, различимых с использованием EDX (вставка на рис. 4).

Дальнейшее увеличение энергии/числа импульсов приводит к значительному превышению порога генерации поверхностных структур в центре кратера, что выражается в разрушении упорядоченных структур и образовании расплавленных участков, при этом по краям кратера продолжается генерация ППС (рис. 4,c).

При облучении образца излучением с длиной волны $1030 \mathrm{~nm}$ действующие механизмы абляции остаются неизменными, однако несколько смещаются энергетические режимы. На рис. 5 видно, что режим откольной абляции наблюдается для энергий 0.08 и $0.12 \mu \mathrm{J}$, при этом внутренняя поверхность кратера остается ровной, таккак „избыточной“ энергии недостаточно для расплавления материала. На вставке рис. 5 видно, что в зоне, где произошла откольная абляция, наблюдается удаление слоя титана (минимальное количество остаточных частиц объясняется разлетом аблировавшего материала от соседних кратеров). При увеличении энергии (от 0.2 до $3.2 \mu \mathrm{J})$ происходит превышение порога плавления материала и образование „внутреннего“ кратера, в центре которого, в свою очередь, начиная с $0.6 \mu \mathrm{J}$, видна зона перезастывшего расплавленного кремния, окруженная кольцом. Таким образом, для энергий 1.2 и $1.6 \mu \mathrm{J}$ абляционные кратеры приобретают трехступенчатый вид, который при дальнейшем увеличении энергии изменяется до „линзовидного“ аналогично кратерам, полученным для больших энергий на длине волны $515 \mathrm{~nm}$.

При многоимпульсном облучении (рис. 6) в соответствии с увеличением вложенной энергии видна последовательная эволюция абляционных кратеров, однако в отличие от кратеров на рис. 4 уже в первом импульсе реализуется механизм откольной абляции, благодаря которой происходит полное удаление пленки, из-за чего в последующих импульсах поверхностные волны возбуждаются уже в подложке, и формируются кремниевые ППС $(\Lambda \sim 0.86 \mu \mathrm{m})$. Дальнейшее повышение энергии/числа импульсов также приводит к разрушению структур в центре кратера (аналогично рис. 4,c).

На основе измерения размеров облученных областей (рис. 7) для обеих длин волн были построены зависимости квадрата ширины абляционного кратера $R_{\mathrm{abl}}^{2}$ от логарифма энергии $\ln E$, которые позволили определить характерные размеры фокальных пятен и величины порогов модификации [8]. Откольная абляция характеризовалась внешними диаметрами соответствующих кратеров, а экспериментальные пороговые значения составили $0.07 \pm 0.01$ и $0.15 \pm 0.04 \mathrm{~J} / \mathrm{cm}^{2}$ (515 и $1030 \mathrm{~nm}$ ), что согласуется с обнаруженной ранее на объемном титане откольной абляцией, возникающей при $0.08 \mathrm{~J} / \mathrm{cm}^{2}(\lambda=800 \mathrm{~nm})$ [9]. Для оценки порога фазового взрыва измерялись диаметры колец застывшего расплава для кратеров, созданных при высоких энергиях в импульсе. Значения пороговой энергии составили $0.32 \pm 0.03 \mathrm{~J} / \mathrm{cm}^{2}(515 \mathrm{~nm})$ и $0.28 \pm 0.02 \mathrm{~J} / \mathrm{cm}^{2}$

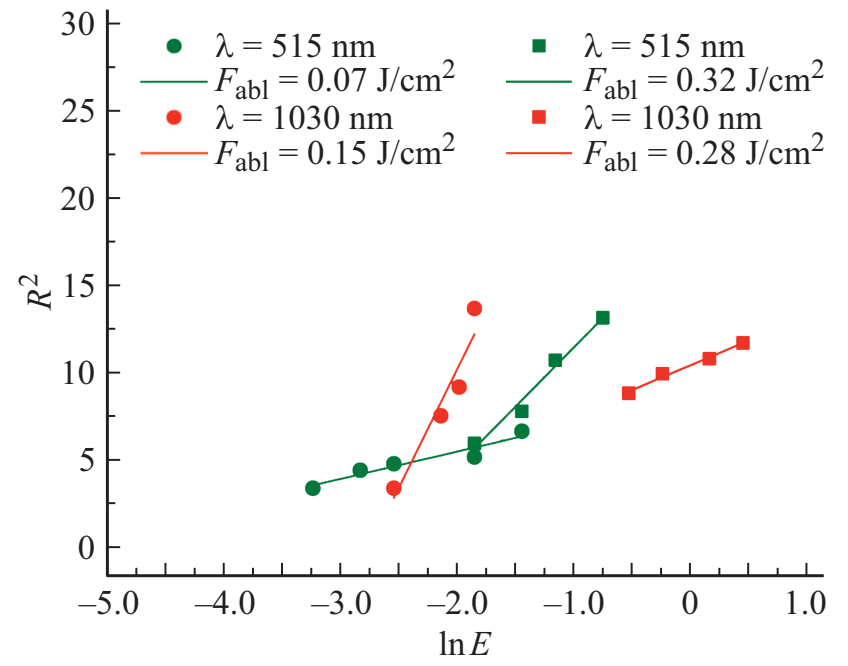

Рис. 7. Зависимость квадрата радиуса области абляции от логарифма энергии импульса. Круглыми маркерами обозначены кратеры откольной абляции, квадратными - абляционные кратеры фазового взрыва.

$(1030 \mathrm{~nm})$, что близко к порогам абляции для объемного титана $\sim 0.3 \mathrm{~J} / \mathrm{cm}^{2}(\lambda=800 \mathrm{~nm})[10]$.

\section{Заключение}

Проведенный эксперимент по облучению пленки титана $300 \mathrm{fs}$ лазерными импульсами на длинах волн 515 и $1030 \mathrm{~nm}$ в одно- и многоимпульсном режимах позволил определить режимы лазерной обработки, при которых реализуется как избирательное удаление титановой пленки без повреждения подложки, так и генерация в ней ППС. Были рассчитаны пороговые значения энергий откольной абляции $\left(0.07 \pm 0.01 \mathrm{~J} / \mathrm{cm}^{2}\right.$ для $515 \mathrm{~nm}$ и $0.15 \pm 0.04 \mathrm{~J} / \mathrm{cm}^{2}$ для $1030 \mathrm{~nm}$ ) и фазового взрыва, которые оказались близки к пороговым значениям для объемного титана $\left(0.32 \pm 0.03 \mathrm{~J} / \mathrm{cm}^{2}\right.$ для $515 \mathrm{~nm}$ и $0.28 \pm 0.02 \mathrm{~J} / \mathrm{cm}^{2}$ для $\left.1030 \mathrm{~nm}\right)$.

\section{Финансирование работы}

Авторы признательны Российскому научному фонду за финансовую поддержку данных исследований в рамках проекта 21-79-30063.

\section{Конфликт интересов}

Авторы заявляют, что у них нет конфликта интересов.

\section{Список литературы}

[1] K.C. Phillips, H.H. Gandhi, E. Mazur, S.K. Sundram. Advances in Optics and Photonics, 7 (4), 684 (2015). DOI: $10.1364 /$ AOP.7.000684 
[2] A.A. Ionin, S.I. Kudryashov, S.V. Makarov, A.O. Levchenko, A.A. Rudenko, I.N. Saraeva, D.A. Zayarny, C.R. Nathala, W. Husinsky. Laser Phys. Lett., 13, 025603 (2016). DOI: $10.1088 / 1612-2011 / 13 / 2 / 025603$

[3] Y.V. Petrov, V.A. Khokhlov, V.V. Zhakhovsky, N.A. Inogamov. Appl. Surf. Sci., 492, 285-297 (2019).

DOI: 10.1016/j.apsusc.2019.05.325

[4] M.V. Shugaev, L.V. Zhigilei. Comput. Mater. Sci., 166, 311317 (2019). DOI: 10.1016/j.commatsci.2019.05.017

[5] S. Petrovic, B. Salatic, D. Perusko, I. Bogdanovic-Radovic, M. Cekada, B. Gakovic, D. Pantelic, M. Trtica, B. Jelenkovic. Laser Phys., 23, 026004 (2013). DOI: 10.1088/1054$660 X / 23 / 2 / 026004$

[6] B. Gakovic, P.A. Danilov, S.I. Kudryashov, D. Milovanovic, A. Radulovic, P. Panjan, A.A. Ionin. Eur. Phys. J. D., 75, 288 (2021). DOI: $10.1140 /$ epjd/s10053-021-00292-4

[7] C. Wu, L.V. Zhigilei. Appl. Phys. A, 1(114), 11 (2014). DOI: $10.1007 / \mathrm{s} 00339-013-8086-4$

[8] J.M. Liu. Optics Lett., 7 (5), 196 (1982).

DOI: 10.1364/OL.7.000196

[9] C. Nathala, A. Ajami, A.A. Ionin, S.I. Kudryashov, S.V. Makarov, T. Ganz, A. Assion, W. Husinsky. Opt. Express, 23, 5915 (2015). DOI: 10.1364/OE.23.005915

[10] M. Ye, C.P. Grigoropoulos. J. Appl. Phys., 89 (9), 5183-5190 (2001). DOI: $10.1063 / 1.1360696$ 